OPEN ACCESS

Edited by:

Hao Yu,

Jining Medical University, China

Reviewed by:

Diego Forero,

Fundación Universitaria del Área Andina, Colombia

Kai Gao,

Chinese Institute for Brain Research, Beijing (CIBR), China

${ }^{*}$ Correspondence:

Anna Starnawska as@biomed.au.dk

Specialty section:

This article was submitted to Behavioral and Psychiatric Genetics, a section of the journal Frontiers in Psychiatry

Received: 20 August 2020

Accepted: 16 February 2021

Published: 01 April 2021

Citation:

Starnawska A and Demontis D (2021) Role of DNA Methylation in Mediating Genetic Risk of Psychiatric Disorders.

Front. Psychiatry 12:596821.

doi: 10.3389/fpsyt.2021.596821

\section{Role of DNA Methylation in Mediating Genetic Risk of Psychiatric Disorders}

\author{
Anna Starnawska ${ }^{1,2,3 *}$ and Ditte Demontis ${ }^{1,2,3}$ \\ ${ }^{1}$ Department of Biomedicine, Aarhus University, Aarhus, Denmark, ${ }^{2}$ The Lundbeck Foundation Initiative for Integrative \\ Psychiatric Research, iPSYCH, Aarhus, Denmark, ${ }^{3}$ Center for Genomics and Personalized Medicine (CGPM), Center for \\ Integrative Sequencing, iSEQ, Aarhus, Denmark
}

Psychiatric disorders are common, complex, and heritable conditions estimated to be the leading cause of disability worldwide. The last decade of research in genomics of psychiatry, performed by multinational, and multicenter collaborative efforts on hundreds of thousands of mental disorder cases and controls, provided invaluable insight into the genetic risk variants of these conditions. With increasing cohort sizes, more risk variants are predicted to be identified in the near future, but there appears to be a knowledge gap in understanding how these variants contribute to the pathophysiology of psychiatric disorders. Majority of the identified common risk single-nucleotide polymorphisms (SNPs) are non-coding but are enriched in regulatory regions of the genome. It is therefore of great interest to study the impact of identified psychiatric disorders' risk SNPs on DNA methylation, the best studied epigenetic modification, playing a pivotal role in the regulation of transcriptomic processes, brain development, and functioning. This work outlines the mechanisms through which risk SNPs can impact DNA methylation levels and provides a summary of current evidence on the role of DNA methylation in mediating the genetic risk of psychiatric disorders.

Keywords: epigenetic regulation, DNA methylation, mQTL, CpG-SNP, GWAS, psychiatric disorder

\section{INTRODUCTION}

Psychiatric disorders, such as major depression (MD), bipolar disorder (BD), schizophrenia (SZ), attention-deficit/hyperactivity disorder (ADHD), autism spectrum disorders (ASD), and anorexia (ANX), are leading causes of disability worldwide and pose a serious challenge to healthcare systems around the world (1). All of these disorders are common and complex phenotypes known for their multifactorial molecular etiologies. Early epidemiological studies of psychiatric disorders determined them to be highly heritable conditions, with a large proportion of variation in liability attributed to additive genetic effects $[\sim 40 \%$ for $\mathrm{MD}(2), \sim 70 \%$ for $\mathrm{BD}$ (3), $\sim 79 \%$ for SZ (4), $\sim 74 \%$ for ADHD (5), $\sim 83 \%$ for ASD (6), $\sim 50-60 \%$ for ANX (7)]. Further advancements in genomics of psychiatry confirmed common and rare genetic variations to underlie these psychiatric disorders and successfully determined loci implicated in these conditions. A significant contribution to the discovery of numerous SNPs associated with the risk of psychiatric disorders was due to large genome-wide association studies (GWASs), the largest and most recent ones reporting the discovery of 102 loci for MD (8), 30 loci for BD (9), 176 loci 
for SZ (10), 12 loci for ADHD (11), five loci for ASD (12), and eight loci for ANX (13), passing the threshold for genomewide significance. Once the inflection point (14) is passed, the number of genome-wide significant loci increases linearly with increasing sample size, and thus the number of GWAS-identified risk loci is expected to increase in future studies when sample sizes get larger (15). However, despite recent GWAS discoveries, the exact molecular mechanisms through which identified risk SNPs, residing in associated risk loci, contribute to psychiatric disorders remain unclear. Majority of the identified risk SNPs is located in non-coding regions of the genome and therefore are not capable of changing amino acid protein sequences. This makes it difficult to understand how their genetic variation contributes to the etiology of these complex phenotypes. The risk SNPs are however consistently reported to be significantly enriched in regulatory regions $(9,11-13,16,17)$ and, based on topological organization of the genome, linked to additional non-coding elements regulating not only proximal but also distant genes $(18,19)$. Along this line, a recent cross-disorder GWAS of eight common psychiatric disorders identified 109 pleiotropic loci affecting more than one psychiatric disorder (20). These risk SNPs were annotated to genes characterized by crucial regulatory role in human neurodevelopment and by their increased expression from the beginning of the second prenatal trimester (20). Altogether, these findings suggest that the identified risk SNPs, also the non-coding ones, may act through regulation of the genome to mediate the risk of psychiatric disorders. The aim of this review is to explore the putative role of DNA methylation as a regulatory mechanism through which the identified risk SNPs could contribute to the development of psychiatric disorders.

\section{IMPORTANCE OF DNA METHYLATION IN PSYCHIATRIC DISORDERS}

DNA methylation, the best studied epigenetic modification, is characterized by an addition of a methyl group to the fifth position of the pyrimidine ring of cytosine base, resulting in 5methylcytosine $(5 \mathrm{mC})$. DNA methylation is dynamic, changes across the individual's life span, and plays a pivotal role in the regulation of human neuronal development, functioning, and survival $(21,22)$. From the moment of conception, DNA methylation levels in the mammalian genome are modifiable by prenatal environmental factors encountered in utero (such as prenatal famine, maternal folic acid supplementation, maternal stress, maternal smoking, among others) (23-28). All of these prenatal exposures have the potential to act through the epigenome to alter the expression of genes related to neuronal function and therefore influence brain development. Additionally, life events (such as childhood maltreatment, trauma, stress) (29-32) and lifestyle choices (diet, tobacco smoking, alcohol use) $(25,33-40)$ modify DNA methylation levels in the genome. Many of these environmental exposures are also strongly associated with psychiatric disorders' risk, giving potential for this epigenetic modification to contribute to the molecular etiology of these conditions. Interestingly, DNA methylation signatures were also associated with brain volume $(41,42)$, brain structure and function $(22,43,44)$, as well as social (45), and cognitive functioning (46), even though the studies were performed in peripheral tissues (blood/saliva). Altogether, the scientific discoveries of impact of DNA methylation on neuronal function, brain structure, and psychiatric disorders' environmental risk factors on human methylome gave rise to numerous epigenome-wide association studies (EWASs) of mental health phenotypes. In contrast to GWAS, in EWAS, it is DNA methylation that is quantified at hundreds of thousands of loci in the human genome in order to identify differentially methylated positions and/or regions associated with a phenotype of interest (47). EWAS of psychiatric disorders identified variations in DNA methylation levels in the genome to be associated with MD, SZ, BD, ASD, ADHD, and ANX (4859 ), as well as disorder trajectory and symptomatology of ADHD and MD $(60,61)$. Interestingly, one EWAS performed in blood samples collected already at individual's birth demonstrated differential DNA methylation in genes involved in fetal brain development and neurogenesis to be associated with psychiatric disorder diagnosis later in life among 22q11.2 deletion carriers (62). However, despite success of these studies to identify differentially methylated sites for these disorders, no clear picture has emerged until now on the role of aberrant DNA methylation levels in the pathophysiology of psychiatric disorders. This is due to difficulties in the interpretation and replication of findings from EWAS of psychiatric disorders across studies arising from relatively low sample sizes, in comparison to GWAS, and DNA methylation being tissue-, developmental stage-, and population-specific (47). Additionally, as environmental factors, stochastic events, individual's genetic background, tissue cellular heterogeneity, as well as technical effects of the methylome quantification process impact the variance of DNA methylation at measured sites, large sample sizes are required to achieve sufficient statistical power to detect true positive differentially methylated sites associated with the disorder $(63,64)$. Therefore, the currently ongoing large multicenter meta-analyses of EWAS results across sites, like meta-EWAS for ASD, ADHD, cognitive functioning (65-67), should provide better insight into the role of human methylome in psychiatric disorders. However, just increasing sample sizes for EWAS may not be sufficient to inform on epigenetic changes underlying psychiatric disorders. Due to the difficulty in gaining access to brain samples, and therefore low sample sizes of brain biobanks, majority of metaEWAS analyses are still performed on methylomic data derived from peripheral tissues, most commonly from blood. As DNA methylation is tissue-specific, findings even from a large metaEWAS may not reflect biological processes in the brain (68). This limitation calls for rigorous replication of EWAS findings from peripheral tissues in human brain samples and encourages the use of additional statistical methods in methylomic studies, e.g., Mendelian randomization, to strengthen causal inference and explore molecular mediation by DNA methylation (69).

Apart from EWASs that commonly aim to identify significant difference in DNA methylation means between cases and controls (47), an increasing number of studies explores the impact of individual's genetic background on DNA methylation 
levels in the genome, with special focus on risk SNPs for common disorders.

\section{HOW CAN DNA METHYLATION BE INFLUENCED BY GENETIC VARIATION?}

Individual's genetic variation can impact DNA methylation levels in the genome, making this epigenetic modification a heritable trait. Heritability of brain DNA methylation in DNA window of size $50 \mathrm{~kb}$ was estimated to range $3-4 \%$ and differed markedly from previously reported blood twin-based mean genomewide heritability of $18 \%(70,71)$. Regardless of the differences in heritability estimates, the heritable DNA methylation loci are highly enriched in open chromatin regions, DNAase I hypersensitive sites, binding sites of transcriptional repressor CTCF, and histone modifications (70, 72). This observation suggests an important epigenetic role of DNA methylation heritable loci in the regulation of chromatin accessibility and gene expression.

Currently, the best studied phenomenon through which genetic variation impacts epigenetic regulation is methylation Quantitative Trait Loci (mQTLs). The mQTL term indicates a statistically significant association between genotype at a SNP and DNA methylation level at nearby (cis-) or distant (trans-) position in the genome $(73,74)$, with majority of mQTLs acting in cis- rather than in trans- manner (75). mQTLs are consistently detected across different populations, developmental stages, and tissue types (76). Studies comparing intraindividual DNA methylation patterns between different brain regions and blood found that DNA methylation levels that were correlated across these tissues were likely to result from mQTLs $(68,77)$. Moreover, the effect of mQTL SNP genotype on DNA methylation level has often the same direction across tissues (76), and methylation measurements by array probes at sites affected by mQTLs have higher signal reliability in comparison to probes that are not (78). These findings highlight the overall stability of DNA methylation signals at loci influenced by mQTL SNPs. Therefore, studying cis- and trans-mQTL regulation of the genome by risk SNPs, in contrast to interpretation of GWAS findings only based on genomic annotation of associated SNPs to their nearest genes, may lead to the discovery of epigenetic dysregulation at nearby or distant genes and so allow for improved interpretation of their role in psychiatric disorders.

Another phenomenon by which sequence variation can impact methylation levels in the genome are CpG-SNPs, a term that relates to $\mathrm{CpG}$ sites that are created or destroyed by SNPs. CpG dinucleotides are highly mutable and their frequency in the human genome is already lower than expected (their occurrence is only $1 \%$ in comparison to the expected $6.25 \%$ based on the probability of 16 possible combinations of dinucleotides) (79). The main reason for this underrepresentation of $\mathrm{CpG}$ sites in the genome is owed to increased mutation rate of methylated cytosines due to their higher rate of spontaneous deamination in comparison to unmethylated cytosines (80). The difference in mutation rate of methylated sites does not however account for all of the mechanisms leading to this discrepancy. Deaminated methylated cytosines result in thymine, while unmethylated cytosines result in uracil, not normally occurring in the DNA, and therefore more efficiently corrected by mismatch repair mechanisms (81). Apart from disappearance of CpG sites, SNPs can also create a new CpG site and therefore provide a new locus for epigenetic regulation. CpG-SNPs are reported to play an important role in allele-specific methylation (82); however, their full impact on common diseases and their possible enrichment in regulatory elements of the genome is currently understudied due to technological constraints to investigate this phenomenon. Majority of human methylomic studies are nowadays performed with methylation arrays that require the use of bisulfite-converted DNA. Results from this array do not reliably distinguish between signals originated from bisulfite-converted unmethylated DNA (measured as T) and between mutated $\mathrm{C}$ to $\mathrm{T} \mathrm{CpG}$ sites. Other, currently less common technologies for methylation studies, like MeDIP-seq, MBD-seq, combination of data from methylation and genotyping arrays, and candidate gene studies performed with MassArray or pyrosequencing systems, provide better identification of CpGSNPs in the genome and their role on DNA methylation levels at the tested site. Altogether, studies using these technological approaches increasingly report CpG-SNP loci to be genomic hotspots for risk of common disorders (immune diseases, diabetes, cancer), but more research is needed to understand their molecular genome-wide role in other complex disorders (83-85).

\section{EVIDENCE FOR THE IMPACT OF METHYLATION QUANTITATIVE TRAIT LOCI ON PSYCHIATRIC DISORDERS}

Studying the impact of genetic variation on the epigenome can fill gaps in our understanding of the mechanisms by which risk SNPs, especially the non-coding ones, contribute to the risk of psychiatric disorders. mQTLs are abundant in the human brain and across various brain regions (86). Interindividual variation in brain DNA methylation levels at numerous loci in the genome was attributed to mQTL effects, and recent studies confirmed several risk SNPs for common psychiatric disorders to act as mQTLs (73). A study performed on dorsolateral prefrontal cortex samples from SZ patients and unaffected matched controls confirmed the abundance of cis-mQTLs in this tissue and reported the detection of mQTL interactions to be independent from the case-control status (87). As the detection of mQTLs is largely independent of the psychiatric disorder status, it indicates a common molecular mechanism conferring regulatory function of SNPs, regardless of the trait they were initially associated with. It therefore allows for an investigation of the impact of associated SNPs on epigenetic regulation in samples collected from unaffected individuals. Study of fetal brain methylomes determined mQTLs in this tissue to be enriched in GWAS risk loci of SZ and to be localized at putative causal loci (affecting the AS3MT gene) associated with the disorder (88). Interestingly, the estimated SZ mQTL risk loci had a larger effect on DNA methylation levels in fetal brain in comparison to their effects in adult brain tissues (prefrontal cortex, striatum, 
cerebellum), supporting the hypothesis of developmental origin of this disorder (88). Both differentially methylated positions associated with SZ through EWAS were enriched in SZ GWAS candidate loci, and SZ GWAS signals were reported to colocalize with blood and brain mQTLs, altogether highlighting the potential causal regulatory impact of SZ risk SNPs (49).

In the case of $\mathrm{BD}$, similarly to findings from $\mathrm{SZ}$, cis-mQTLs across the genome were found to be enriched in variants associated with BD (89). Cross-tissue cis-mQTLs overlapping between blood, brain, and saliva were strongly enriched in SZ-associated variants but not with $\mathrm{BD}$, what might indicate higher tissue specificity in molecular pathology of BD (89). This observation was supported by an independent study where the top susceptibility variants for $\mathrm{BD}$ were found to be enriched in mQTLs in the cerebellum, but not in transformed lymphocytes (90). However, as the transformation alters the methylomic landscape of cells, it is unclear how this process impacts methylation levels at mQTL loci and further detection of the enrichment (91). Candidate gene study of BD risk SNPs in CACNA1C confirmed its risk variants to act as cismQTLs in blood (92). The study found also that variance in DNA methylation levels at CACNA1C cis-mQTL sites was independently associated not only with genotypes of $\mathrm{BD}$ risk SNPs but also with individual's sex and BD diagnosis itself (92). Therefore, to what extent DNA methylation levels at mQTL regulatory sites across the genome are modifiable by cell transformations, additional environmental exposures, and intraindividual characteristics is currently understudied, but the impact of these factors on methylome in a tissue-specific manner could hinder the detection of such cross-tissue signals in $\mathrm{BD}$ and other phenotypes.

In $\mathrm{MD}$, representing another affective disorder, there is strong evidence that at least nine of the MD GWAS-associated risk SNPs act as cis-mQTLs (16). Also, a recent study that proposed a bloodbased methylation risk score for MD prediction found that 71 CpG sites, out of 196 sites contributing to the predictor, were blood mQTLs during middle-age time point and $11 \mathrm{CpG}$ sites regulated by $\mathrm{mQTL}$ also associated with $\mathrm{MD}$ after false discovery rate (FDR) correction (93).

In the case of childhood-onset psychiatric disorders (ASD and ADHD), the cis-mQTLs in blood, brain, and fetal brain were reported among identified risk SNPs (94). Moreover, the applied mQTL approach allowed for the refinement of ADHD and ASD risk loci and identification of additional genes with altered epigenetic regulation due to risk SNPs of these disorders, not linked to these SNPs before based on annotation to the closest gene (94). ASD GWAS risk SNPs were also associated with altered methylation levels in the genome in neonatal blood, and the cis-mQTLs co-localized with ASD GWAS findings, highlighting potential regulatory variation to be associated with the disorder (94). Apart from the abovementioned psychiatric disorders, risk SNPs of other mental health conditions (e.g., alcohol dependence disorder) were reported to be mQTLs in post-mortem prefrontal cortex and to be enriched in GWASidentified risk loci of the studied phenotypes (95). Additionally, a recent conditional GWAS, aimed to identify disorder-specific SNPs for five psychiatric disorders (SZ, BD, MD, ASD, ADHD), reported that the associated disorder-specific SNPs also act as cismQTLs in fetal and adult brain tissues for the conditional traits (18 methylation sites were identified for SZ, two for BD, 37 for MD, eight for ADHD, and six for ASD) (96). Overall, there is increasing evidence that the risk SNPs of psychiatric disorders impact epigenetic regulation by acting as mQTLs across tissues and developmental stages. An overview of studies providing evidence on DNA methylation changes due to mQTL SNPs or at CpG-SNP positions associated with psychiatric disorders is included in Table $\mathbf{1 .}$

\section{EVIDENCE FOR THE IMPACT OF CpG-SNPs ON PSYCHIATRIC DISORDERS}

In contrast to mQTLs, where the genotype of an SNP is associated with altered methylation level at a nearby or distant cytosine in the genome, the CpG-SNPs allow for variation in methylation levels and in sequence at the exact position of the SNP. However, due to technological constraints to reliably investigate the variation in methylation levels at CpG-SNPs, not many studies investigated these associations with psychiatric disorders and some studies investigated only the link between genotypes at CpG-SNPs and mental health phenotypes (102). An epigenetic study of CpG-SNPs that tested if groups of cases and controls with the same genotype at these sites differ in methylation levels at these positions identified 27 CpG-SNPs associated with $\mathrm{MD}$ and the results to be overrepresented among findings from GWAS reports of MD and MD-related phenotypes (99). A similar study utilizing the same analytical approach, but in the context of psychotic disorders, identified a CpGSNP rs3796293 in IL1RAP and its altered methylation to be significantly associated with $\mathrm{SZ}$ and have the same direction of effect in blood and brain of SZ patients (100). A candidate gene study of CpG-SNPs in prodynorphin, associated with alcohol dependence, showed elevated methylation at these sites in the brain of human alcoholics (101). Even though there is some evidence that methylation levels at CpG-SNPs can be linked with psychiatric disorders, more studies performed on samples encompassing different phenotypes, tissues, and developmental stages are required to comprehensively evaluate the role of epigenetic regulation at these sites in molecular etiology of psychiatric disorders.

\section{DISCUSSION}

With the fast-growing number of identified risk SNPs associated with psychiatric disorders, there is an urgent need for an identification of the affected biological mechanisms. Especially in case of non-coding SNPs, this can be difficult to determine. It has been established that identified common risk SNPs are enriched in chromatin regulatory regions, epigenetic marks, and genes important for brain development and functioning. Recent studies provided additional evidence that the risk SNPs for psychiatric disorders can act as mQTLs, leading to an altered DNA methylation landscape in the genome. Overall, the studies show that interpretation of GWAS results can benefit from 
TABLE 1 | Overview of studies providing evidence on changes in DNA methylation associated with risk SNPs for common psychiatric disorders.

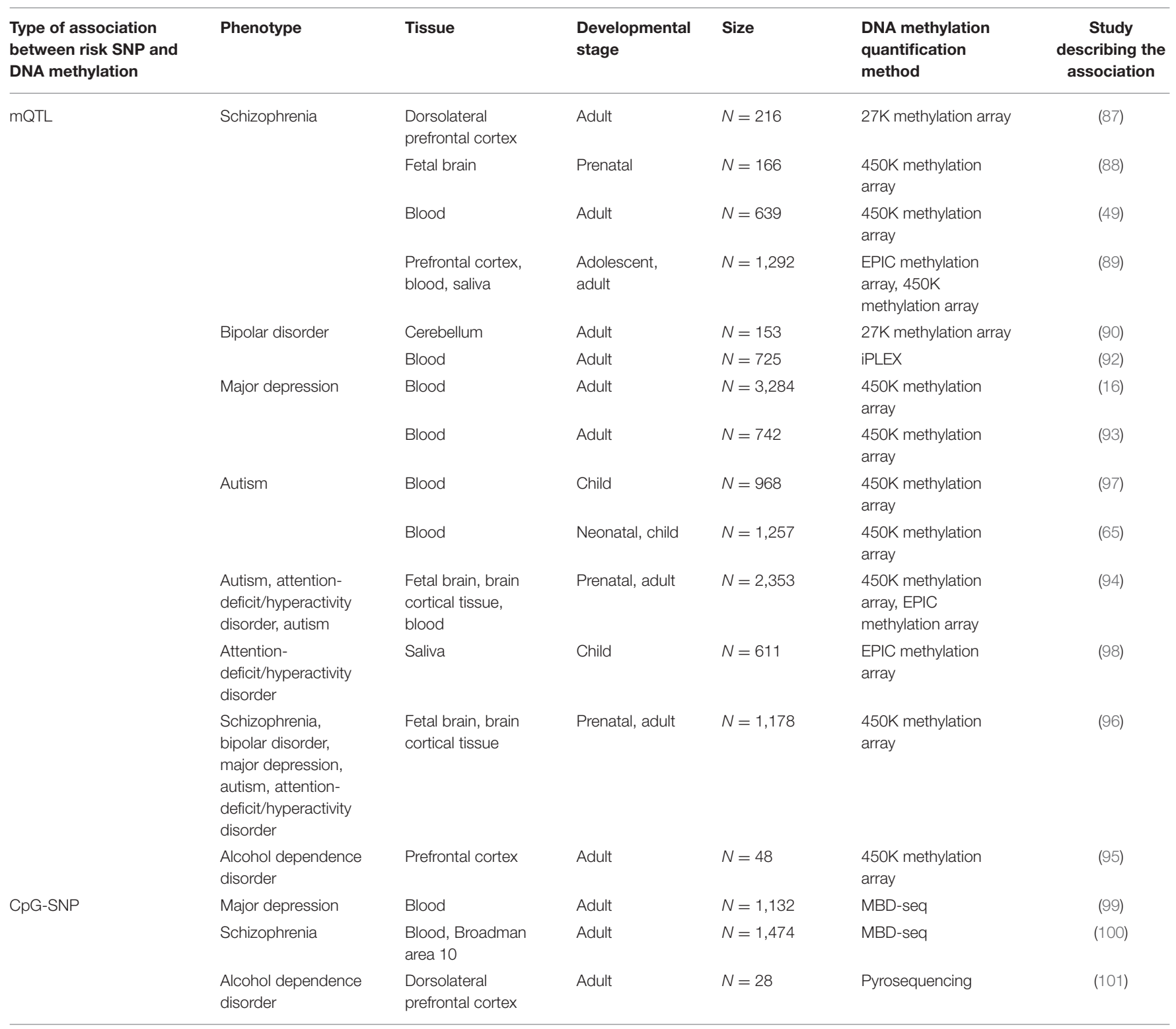

mQTL, methylation Quantitative Trait Locus; SNP, single-nucleotide polymorphism.

including mQTL approaches in fine-mapping of risk loci to identify causal variants and variant prioritization. However, in order to fully understand the impact of risk SNP mQTLs on the development and trajectory of psychiatric disorders, more systematic studies on the human methylome are needed. For example, the abovementioned studies of risk SNPs and mQTLs in psychiatric disorders utilized data generated from different versions of methylation arrays (differing by types of genomic regulatory regions that they cover and number of loci tested), tissues (fetal brain, adult brain, different brain regions, blood, saliva), and developmental stages (fetal development, neonatal, adult, middle-aged). These mQTLs were also calculated based on cohorts with varying sample sizes, which may limit statistical power to detect some mQTLs, and therefore reported mQTLs may not be directly comparable across the studies. The mQTL datasets used in each study were specifically chosen to test particular hypotheses relevant for each investigated disorder, but there is still a lack of comprehensive studies of psychiatric disorder risk SNP mQTLs across lifetime and tissues. Such studies should be performed with the largest methylation arrays or whole-genome methylomic data, if possible, to provide more information on putative mQTL-regulated loci. It is also worth noting that the majority of studies investigated only cis-mQTL regulation, which is more abundant in the human genome than trans-, but lacks information on long distance or acrosschromosome impact of risk SNPs on variation in methylation.

Apart from the function of risk SNPs for psychiatric disorders as mQTLs, it is also important to study expression QTLs 


\section{Perform GWAS to identify risk SNPs for a psychiatric disorder}

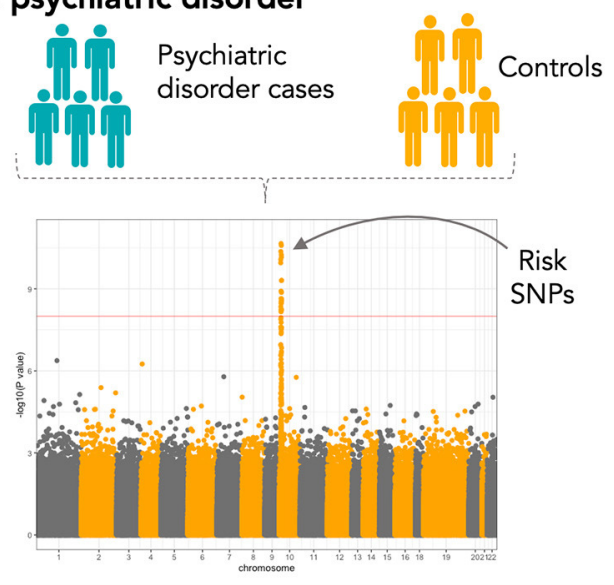

\section{Visualize mOTL results for the significant SNP-CpG site association}

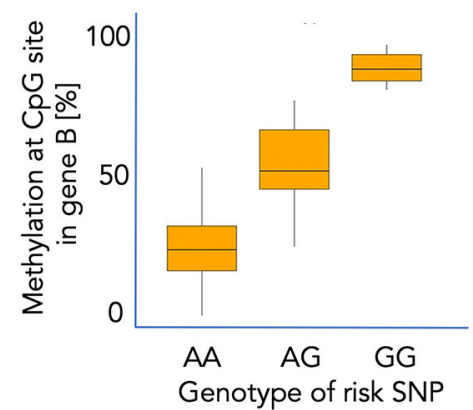

In this example genotype $G$ at the risk SNP is associated with increased DNA methylation levels ( $)$ at $\mathrm{CpG}$ site in gene B

\section{Perform mQTL analysis to test if genotype at the risk SNP is associated with DNA methylation levels}

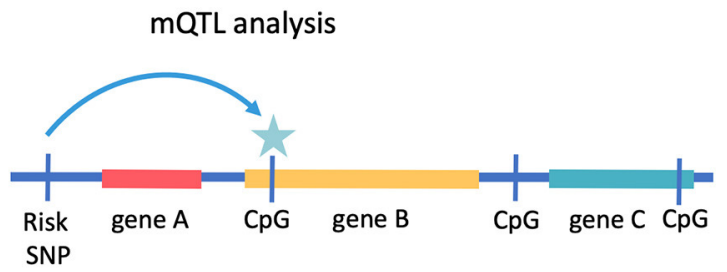

In this example genotype at the risk SNP is associated with DNA methylation change $(t)$ at CpG site in gene $B$, but not gene $A$ nor gene $C$

\section{Provide functional interpretation of mQTL findings}

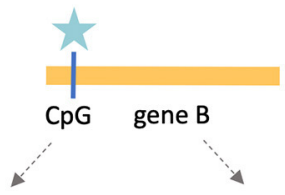

Genomic context of the CpG:

- Promoter region

- Gene body

- CpG island, shore, shelf

- Exon-intron boundary

- Overlap with regulatory regions
Functional analysis of gene $B$ :

- Literature review on gene $B$ function

- Gene B membership in molecular pathways

- eQTL interactions for gene B expression across tissues

- Interactions between protein B and drugs

FIGURE 1 | Recommended workflow for using DNA methylation data for interpretation of the functional impact of risk single-nucleotide polymorphisms (SNPs) for psychiatric disorders.

(eQTLs) to gain insight into downstream effects of variation in DNA methylation due to risk SNPs on gene expression. DNA methylation plays a pivotal role in the regulation of transcriptional processes such as gene expression, alternative promoter usage, as well as gene splicing. It is established that mQTLs co-localize with eQTLs $(86,103-105)$ and fetal brain mQTLs show significant overlap with SNPs also associated with gene expression in the brain (88). A recent study performed in blood and fetal and adult brain provided also evidence for pleiotropic effects of associated mental disorder common risk SNPs (for ADHD and ASD) on DNA methylation levels and gene expression (94). All this emerging evidence points to DNA methylation as a putative regulatory mechanism to mediate mental disorder risk from associated SNPs. We therefore recommend that in order to gain deeper understanding of the functional role of risk SNPs in psychiatric disorders, GWAS findings should be subjected to mQTL analysis (Figure 1). Results from mQTL analysis should be further interpreted to study (i) the genomic context of identified CpG sites to evaluate their putative role on gene expression, splicing patterns, and impact on other regulatory elements of the genome and (ii) the molecular function of genes annotated to $\mathrm{CpG}$ sites with altered methylation patterns (Figure 1). Findings from mQTL analysis should also be coupled with eQTL information by, e.g., co-localization analysis to provide a more complete overview of the functional impact of risk SNPs.

These recommendations overall highlight the importance of combining genomic, environmental, expression, and epigenomic data to study psychiatric phenotypes. The scientific community therefore should work toward performing such multi-omics studies in large sample sizes across multiple relevant tissues, developmental stages, and populations to gain a deeper understanding of the complex multifactorial interplay influencing the development and trajectories of mental health phenotypes.

In conclusion, studies on how risk SNPs affect intermediate phenotypes, like DNA methylation or gene expression through mQTLs and eQTLs and how these in turn vary 
with complex human diseases provide valuable insight into disease etiology and may provide new knowledge for the development of future treatment or preventive approaches for psychiatric disorders.

\section{AUTHOR CONTRIBUTIONS}

AS wrote the first draft. DD contributed with invaluable discussions, information, and manuscript review. Both authors

\section{REFERENCES}

1. Vos T, Abajobir AA, Abate KH, Abbafati C, Abbas KM, Abd-Allah F, et al. Global, regional, and national incidence, prevalence, and years lived with disability for 328 diseases and injuries for 195 countries, 1990-2016: a systematic analysis for the global burden of disease study 2016. Lancet. (2017) 390:1211-59. doi: 10.1016/S0140-6736(17)32154-2

2. Sullivan PF, Neale MC, Kendler KS. Genetic epidemiology of major depression: review and meta-analysis. Am J Psychiatry. (2000) 157:155262. doi: 10.1176/appi.ajp.157.10.1552

3. McGuffin P, Rijsdijk F, Andrew M, Sham P, Katz R, Cardno A. The heritability of bipolar affective disorder and the genetic relationship to unipolar depression. Arch Gen Psychiatry. (2003) 60:497. doi: 10.1001/archpsyc.60.5.497

4. Hilker R, Helenius D, Fagerlund B, Skytthe A, Christensen K, Werge TM, et al. Heritability of schizophrenia and schizophrenia spectrum based on the nationwide danish twin register. Biol Psychiatry. (2018) 83:4928. doi: 10.1016/j.biopsych.2017.08.017

5. Faraone SV, Larsson H. Genetics of attention deficit hyperactivity disorder. Mol Psychiatry. (2019) 24:562-75. doi: 10.1038/s41380-018-0070-0

6. Sandin S, Lichtenstein P, Kuja-Halkola R, Hultman C, Larsson H, Reichenberg A. The heritability of autism spectrum disorder. JAMA. (2017) 318:1182-4. doi: 10.1001/jama.2017.12141

7. Yilmaz Z, Hardaway JA, Bulik CM. Genetics and epigenetics of eating disorders. Adv Genomics Genet. (2015) 5:131-50. doi: 10.2147/AGG.S55776

8. Howard DM, Adams MJ, Clarke TK, Hafferty JD, Gibson J, Shirali M, et al. Genome-wide meta-analysis of depression identifies 102 independent variants and highlights the importance of the prefrontal brain regions. Nat Neurosci. (2019) 22:343-52. doi: 10.1038/s41593-018-0326-7

9. Stahl EA, Breen G, Forstner AJ, McQuillin A, Ripke S, Trubetskoy V, et al. Genome-wide association study identifies 30 loci associated with bipolar disorder. Nat Genet. (2019) 51:793-803. doi: 10.1038/s41588-019-0397-8

10. Lam M, Chen CY, Li Z, Martin AR, Bryois J, Ma X, et al. Comparative genetic architectures of schizophrenia in East Asian and European populations. Nat Genet. (2019) 51:1670-8. doi: 10.1038/s41588-019-0512-x

11. Demontis D, Walters RK, Martin J, Mattheisen M, Als TD, Agerbo $\mathrm{E}$, et al. Discovery of the first genome-wide significant risk loci for attention deficit/hyperactivity disorder. Nat Genet. (2019) 51:6375. doi: 10.1038/s41588-018-0269-7

12. Grove J, Ripke S, Als TD, Mattheisen M, Walters RK, Won $\mathrm{H}$, et al. Identification of common genetic risk variants for autism spectrum disorder. Nat Genet. (2019) 51:431-44. doi: 10.1038/s41588-019-0344-8

13. Watson HJ, Yilmaz Z, Thornton LM, Hübel C, Coleman JRI, Gaspar HA, et al. Genome-wide association study identifies eight risk loci and implicates metabo-psychiatric origins for anorexia nervosa. Nat Genet. (2019) 51:120714. doi: 10.1038/s41588-019-0439-2

14. Levinson DF, Mostafavi S, Milaneschi Y, Rivera M, Ripke S, Wray NR, et al. Genetic studies of major depressive disorder: Why are there no genomewide association study findings and what can we do about it? Biol Psychiatry. (2014) 76:510-2. doi: 10.1016/j.biopsych.2014.07.029

15. Visscher PM, Wray NR, Zhang Q, Sklar P, McCarthy MI, Brown MA, et al. 10 Years of GWAS discovery: biology, function, and translation. Am J Hum Genet. (2017) 101:5-22. doi: 10.1016/j.ajhg.2017. 06.005 contributed to writing of the final version of the manuscript and approved the submitted version.

\section{FUNDING}

This study was funded by the Lundbeck Foundation (Denmark) and is part of The Lundbeck Foundation Initiative for Integrative Psychiatric Research (iPSYCH). The study was also supported by H2020 Program (Grant no. 667302, CoCA).

16. Wray NR, Ripke S, Mattheisen M, Trzaskowski M, Byrne EM, Abdellaoui A, et al. Genome-wide association analyses identify 44 risk variants and refine the genetic architecture of major depression. Nat Genet. (2018) 50:66881. doi: 10.1038/s41588-018-0090-3

17. Ripke S, Neale BM, Corvin A, Walters JTR, Farh K-H, Holmans PA, et al. Biological insights from 108 schizophrenia-associated genetic loci. Nature. (2014) 511:421-7. doi: 10.1038/nature13595

18. Barešić A, Nash AJ, Dahoun $T$, Howes $O$, Lenhard $B$. Understanding the genetics of neuropsychiatric disorders: the potential role of genomic regulatory blocks. Mol Psychiatry. (2020) 25:6-18. doi: 10.1038/s41380-019-0518-x

19. Akbarian S, Liu C, Knowles JA, Vaccarino FM, Farnham PJ, Crawford GE, et al. The PsychENCODE project. Nat Neurosci. (2015) 18:170712. doi: $10.1038 / \mathrm{nn} .4156$

20. Lee PH, Anttila V, Won H, Feng YCA, Rosenthal J, Zhu Z, et al. Genomic relationships, novel loci, and pleiotropic mechanisms across eight psychiatric disorders. Cell. (2019) 179:1469-82.e11. doi: 10.1016/j.cell.2019.11.020

21. Feng J, Fouse S, Fan G. Epigenetic regulation of neural gene expression and neuronal function. Pediatr Res. (2007) 61:58R-63R. doi: 10.1203/pdr.0b013e3180457635

22. Wheater ENW, Stoye DQ, Cox SR, Wardlaw JM, Drake AJ, Bastin ME, et al. DNA methylation and brain structure and function across the life course: A systematic review. Neurosci Biobehav Rev. (2020) 113:13356. doi: 10.1016/j.neubiorev.2020.03.007

23. Wadhwa PD, Buss C, Entringer S, Swanson JM. Developmental origins of health and disease: brief history of the approach and current focus on epigenetic mechanisms. Semin Reprod Med. (2009) 27:35868. doi: 10.1055/s-0029-1237424

24. Joubert BR, den Dekker HT, Felix JF, Bohlin J, Ligthart S, Beckett E, et al. Maternal plasma folate impacts differential DNA methylation in an epigenome-wide meta-analysis of newborns. Nat Commun. (2016) 7:10577. doi: $10.1038 /$ ncomms 10577

25. Heijmans BT, Tobi EW, Stein AD, Putter H, Blauw GJ, Susser ES, et al. Persistent epigenetic differences associated with prenatal exposure to famine in humans. Proc Natl Acad Sci USA. (2008) 105:170469. doi: 10.1073/pnas.0806560105

26. Tobi EW, Goeman JJ, Monajemi R, Gu H, Putter H, Zhang Y, et al. DNA methylation signatures link prenatal famine exposure to growth and metabolism. Nat Commun. (2014) 5:5592. doi: 10.1038/ncomms6592

27. Richmond RC, Simpkin AJ, Woodward G, Gaunt TR, Lyttleton O, McArdle WL, et al. Prenatal exposure to maternal smoking and offspring DNA methylation across the lifecourse: findings from the avon longitudinal study of parents and children (ALSPAC). Hum Mol Genet. (2015) 24:220117. doi: $10.1093 / \mathrm{hmg} / \mathrm{ddu} 739$

28. Braithwaite EC, Kundakovic M, Ramchandani PG, Murphy SE, Champagne FA. Maternal prenatal depressive symptoms predict infant NR3C1 $1 \mathrm{~F}$ and BDNF IV DNA methylation. Epigenetics. (2015) 10:408-17. doi: 10.1080/15592294.2015.1039221

29. Peter CJ, Fischer LK, Kundakovic M, Garg P, Jakovcevski M, Dincer A, et al. DNA methylation signatures of early childhood malnutrition associated with impairments in attention and cognition. Biol Psychiatry. (2016) 80:76574. doi: 10.1016/j.biopsych.2016.03.2100

30. Saunderson EA, Spiers H, Mifsud KR, Gutierrez-Mecinas M, Trollope AF, Shaikh A, et al. Stress-induced gene expression and behavior are 
controlled by DNA methylation and methyl donor availability in the dentate gyrus. Proc Natl Acad Sci USA. (2016) 113:4830-5. doi: 10.1073/pnas.15248 57113

31. Bustamante AC, Aiello AE, Galea S, Ratanatharathorn A, Noronha C, Wildman DE, et al. Glucocorticoid receptor DNA methylation, childhood maltreatment and major depression. J Affect Disord. (2016) 206:1818. doi: 10.1016/j.jad.2016.07.038

32. Essex MJ, Thomas Boyce W, Hertzman C, Lam LL, Armstrong JM, Neumann SMA, et al. Epigenetic vestiges of early developmental adversity: childhood stress exposure and DNA methylation in adolescence. Child Dev. (2013) 84:58-75. doi: 10.1111/j.1467-8624.2011.01641.x

33. Liu C, Marioni RE, Hedman ÅK, Pfeiffer L, Tsai P-C, Reynolds LM, et al. A DNA methylation biomarker of alcohol consumption. Mol Psychiatry. (2018) 23:422-33. doi: $10.1038 / \mathrm{mp} .2016 .192$

34. Zeilinger S, Kühnel B, Klopp N, Baurecht H, Kleinschmidt A, Gieger C, et al. Tobacco smoking leads to extensive genome-wide changes in DNA methylation. PLoS ONE. (2013) 8:e63812. doi: 10.1371/journal.pone.0063812

35. Meng Q, Ying Z, Noble E, Zhao Y, Agrawal R, Mikhail A, et al. Systems nutrigenomics reveals brain gene networks linking metabolic and brain disorders. EBioMedicine. (2016) 7:157-66. doi: 10.1016/j.ebiom.2016.04.008

36. Denham J, Marques FZ, Bruns EL, O’Brien BJ, Charchar FJ. Epigenetic changes in leukocytes after 8 weeks of resistance exercise training. Eur J Appl Physiol. (2016) 116:1245-53. doi: 10.1007/s00421-016-3382-2

37. Fragou D, Zanos P, Kouidou S, Njau S, Kitchen I, Bailey A, et al. Effect of chronic heroin and cocaine administration on global DNA methylation in brain and liver. Toxicol Lett. (2013) 218:260-5. doi: 10.1016/j.toxlet.2013.01.022

38. Palma-Gudiel H, Córdova-Palomera A, Eixarch E, Deuschle M, Fañanás L. Maternal psychosocial stress during pregnancy alters the epigenetic signature of the glucocorticoid receptor gene promoter in their offspring: a meta-analysis. Epigenetics. (2015) 10:893-902. doi: 10.1080/15592294.2015.1088630

39. Palacios-García I, Lara-Vásquez A, Montiel JF, Díaz-Véliz GF, Sepúlveda $\mathrm{H}$, Utreras E, et al. Prenatal stress down-regulates reelin expression by methylation of its promoter and induces adult behavioral impairments in rats. PLoS ONE. (2015) 10:e0117680. doi: 10.1371/journal.pone.0117680

40. Rzehak P, Saffery R, Reischl E, Covic M, Wahl S, Grote V, et al. Maternal smoking during pregnancy and dna-methylation in children at age 5.5 years: epigenome-wide-analysis in the european childhood obesity project (CHOP)-study. PLoS ONE. (2016) 11:e0155554. doi: 10.1371/journal.pone.0155554

41. Liu J, Siyahhan Julnes P, Chen J, Ehrlich S, Walton E, Calhoun VD. The association of DNA methylation and brain volume in healthy individuals and schizophrenia patients. Schizophr Res. (2015) 169:44752. doi: 10.1016/j.schres.2015.08.035

42. Booij L, Szyf M, Carballedo A, Frey EM, Morris D, Dymov S, et al. DNA methylation of the serotonin transporter gene in peripheral cells and stress-related changes in hippocampal volume: a study in depressed patients and healthy controls. PLoS ONE. (2015) 10:e0119061. doi: 10.1371/journal.pone.0119061

43. Shelton AL, Cornish KM, Kolbe S, Clough M, Slater HR, Li X, et al. Brain structure and intragenic DNA methylation are correlated, and predict executive dysfunction in fragile X premutation females. Transl Psychiatry. (2016) 6:e984. doi: 10.1038/tp.2016.250

44. Han KM, Won E, Sim Y, Kang J, Han C, Kim YK, et al. Influence of FKBP5 polymorphism and DNA methylation on structural changes of the brain in major depressive disorder. Sci Rep. (2017) 7:42621. doi: 10.1038/srep42621

45. Jack A, Connelly JJ, Morris JP. DNA methylation of the oxytocin receptor gene predicts neural response to ambiguous social stimuli. Front Hum Neurosci. (2012) 6:280. doi: 10.3389/fnhum.2012.00280

46. Starnawska A, Tan Q, Lenart A, McGue M, Mors O, Børglum AD, et al. Blood DNA methylation age is not associated with cognitive functioning in middle-aged monozygotic twins. Neurobiol Aging. (2017) 9:413. doi: 10.3389/fnagi.2017.00413

47. Rakyan VK, Down TA, Balding DJ, Beck S. Epigenome-wide association studies for common human diseases. Nat Rev Genet. (2011) 12:52941. doi: $10.1038 / \mathrm{nrg} 3000$
48. Aberg KA, McClay JL, Nerella S, Clark S, Kumar G, Chen W, et al. Methylome-wide association study of schizophrenia: identifying blood biomarker signatures of environmental insults. JAMA Psychiatry. (2014) 71:255-64. doi: 10.1001/jamapsychiatry.2013.3730

49. Hannon E, Dempster E, Viana J, Burrage J, Smith AR, Macdonald R, et al. An integrated genetic-epigenetic analysis of schizophrenia: evidence for co-localization of genetic associations and differential DNA methylation. Genome Biol. (2016) 17:176. doi: 10.1186/s13059-016-1041-x

50. Abdolmaleky HM, Cheng KH, Faraone SV, Wilcox M, Glatt SJ, Gao F, et al. Hypomethylation of MB-COMT promoter is a major risk factor for schizophrenia and bipolar disorder. Hum Mol Genet. (2006) 15:313245. doi: $10.1093 / \mathrm{hmg} / \mathrm{ddl} 253$

51. Montano C, Taub MA, Jaffe A, Briem E, Feinberg JI, Trygvadottir R, et al. Association of DNA methylation differences with schizophrenia in an epigenome-wide association study. JAMA Psychiatry. (2016) 73:50614. doi: 10.1001/jamapsychiatry.2016.0144

52. Dempster EL, Pidsley R, Schalkwyk LC, Owens S, Georgiades A, Kane F, et al. Disease-associated epigenetic changes in monozygotic twins discordant for schizophrenia and bipolar disorder. Hum Mol Genet. (2011) 20:478696. doi: $10.1093 / \mathrm{hmg} / \mathrm{ddr} 416$

53. Córdova-Palomera A, Fatjó-Vilas M, Gastó C, Navarro V, Krebs MO, Fañanás L. Genome-wide methylation study on depression: differential methylation and variable methylation in monozygotic twins. Transl Psychiatry. (2015) 5:e557. doi: 10.1038/tp.2015.49

54. Kato T, Iwamoto K. Comprehensive DNA methylation and hydroxymethylation analysis in the human brain and its implication in mental disorders. Neuropharmacology. (2014) 80:133-9. doi: 10.1016/j.neuropharm.2013.12.019

55. Mill J, Tang T, Kaminsky Z, Khare T, Yazdanpanah S, Bouchard $\mathrm{L}$, et al. Epigenomic profiling reveals DNA-methylation changes associated with major psychosis. Am J Hum Genet. (2008) 82:696-711. doi: 10.1016/j.ajhg.2008.01.008

56. Ladd-Acosta C, Hansen KD, Briem E, Fallin MD, Kaufmann WE, Feinberg AP. Common DNA methylation alterations in multiple brain regions in autism. Mol Psychiatry. (2014) 19:862-71. doi: 10.1038/mp.2013.114

57. Nardone S, Sams DS, Reuveni E, Getselter D, Oron O, Karpuj M, et al. DNA methylation analysis of the autistic brain reveals multiple dysregulated biological pathways. Transl Psychiatry. (2014) 4:e433. doi: 10.1038/tp.2014.70

58. Ciernia AV, LaSalle J. The landscape of DNA methylation amid a perfect storm of autism aetiologies. Nat Rev Neurosci. (2016) 17:41123. doi: $10.1038 /$ nrn. 2016.41

59. Steiger H, Booij L, Kahan E, McGregor K, Thaler L, Fletcher E, et al. A longitudinal, epigenome-wide study of DNA methylation in anorexia nervosa: results in actively ill, partially weight-restored, long-term remitted and non-eating-disordered women. J Psychiatry Neurosci. (2019) 44:20513. doi: $10.1503 /$ jpn. 170242

60. Walton E, Pingault JB, Cecil CAM, Gaunt TR, Relton CL, Mill J, et al. Epigenetic profiling of ADHD symptoms trajectories: a prospective, methylome-wide study. Mol Psychiatry. (2017) 22:250-6. doi: 10.1038/mp.2016.85

61. Starnawska A, Tan Q, Soerensen M, McGue M, Mors O, Børglum $\mathrm{AD}$, et al. Epigenome-wide association study of depression symptomatology in elderly monozygotic twins. Transl Psychiatry. (2019) 9:214. doi: 10.1038/s41398-019-0548-9

62. Starnawska A, Hansen CS, Sparsø T, Mazin W, Olsen L, Bertalan M, et al. Differential DNA methylation at birth associated with mental disorder in individuals with 22q11.2 deletion syndrome. Transl Psychiatry. (2017) 7:e1221. doi: 10.1038/tp.2017.181

63. Heijmans BT, Mill J. Commentary: the seven plagues of epigenetic epidemiology. Int J Epidemiol. (2012) 41:74-8. doi: 10.1093/ije/dyr225

64. Tsai PC, Bell JT. Power and sample size estimation for epigenome-wide association scans to detect differential DNA methylation. Int J Epidemiol. (2015) 44:1429-41. doi: 10.1093/ije/dyv041

65. Hannon E, Schendel D, Ladd-Acosta C, Grove J, iPSYCH-Broad ASD Group iPSYCH-BA, Hansen CS, et al. Elevated polygenic burden for autism is associated with differential DNA methylation at birth. Genome Med. (2018) 10:19. doi: 10.1186/s13073-018-0527-4 
66. van Dongen J, Zilhão NR, Sugden K, Heijmans BT, 't Hoen PAC, van Meurs J, et al. Epigenome-wide association study of attentiondeficit/hyperactivity disorder symptoms in adults. Biol Psychiatry. (2019) 86:599-607. doi: 10.1016/j.biopsych.2019.02.016

67. Marioni RE, McRae AF, Bressler J, Colicino E, Hannon E, Li S, et al. Metaanalysis of epigenome-wide association studies of cognitive abilities. $\mathrm{Mol}$ Psychiatry. (2018) 23:2133-44. doi: 10.1038/s41380-017-0008-y

68. Hannon E, Lunnon K, Schalkwyk L, Mill J. Interindividual methylomic variation across blood, cortex, and cerebellum: implications for epigenetic studies of neurological and neuropsychiatric phenotypes. Epigenetics. (2015) 10:1024-32. doi: 10.1080/15592294.2015.1100786

69. Walton E, Relton CL, Caramaschi D. Using openly accessible resources to strengthen causal inference in epigenetic epidemiology of neurodevelopment and mental health. Genes. (2019) 10:193. doi: 10.3390/genes10030193

70. Quon G, Lippert C, Heckerman D, Listgarten J. Patterns of methylation heritability in a genome-wide analysis of four brain regions. Nucleic Acids Res. (2013) 41:2095-104. doi: 10.1093/nar/gks1449

71. Bell JT, Tsai PC, Yang TP, Pidsley R, Nisbet J, Glass D, et al. Epigenomewide scans identify differentially methylated regions for age and agerelated phenotypes in a healthy ageing population. PLoS Genet. (2012) 8:e1002629. doi: 10.1371/journal.pgen.1002629

72. Banovich NE, Lan X, McVicker G, van de Geijn B, Degner JF, Blischak JD, et al. Methylation QTLs are associated with coordinated changes in transcription factor binding, histone modifications, and gene expression levels. PLoS Genet. (2014) 10:e1004663. doi: 10.1371/journal.pgen.1004663

73. Zhang D, Cheng L, Badner JA, Chen C, Chen Q, Luo W, et al. Genetic control of individual differences in gene-specific methylation in human brain. Am J Hum Genet. (2010) 86:411-9. doi: 10.1016/j.ajhg.2010.02.005

74. Bell JT, Pai AA, Pickrell JK, Gaffney DJ, Pique-Regi R, Degner JF, et al. DNA methylation patterns associate with genetic and gene expression variation in HapMap cell lines. Genome Biol. (2011) 12:R10. doi: 10.1186/gb-2011-12-6-405

75. McRae AF, Marioni RE, Shah S, Yang J, Powell JE, Harris SE, et al. Identification of 55,000 Replicated DNA Methylation QTL. Sci Rep. (2018) 8:17605. doi: 10.1038/s41598-018-35871-w

76. Smith AK, Kilaru V, Kocak M, Almli LM, Mercer KB, Ressler KJ, et al. Methylation quantitative trait loci (meQTLs) are consistently detected across ancestry, developmental stage, and tissue type. BMC Genomics. (2014) 15:145. doi: 10.1186/1471-2164-15-145

77. Davies MN, Volta M, Pidsley R, Lunnon K, Dixit A, Lovestone S, et al. Functional annotation of the human brain methylome identifies tissuespecific epigenetic variation across brain and blood. Genome Biol. (2012) 13:R43. doi: 10.1186/gb-2012-13-6-r43

78. Sugden K, Hannon EJ, Arseneault L, Belsky DW, Corcoran DL, Fisher HL, et al. Patterns of reliability: assessing the reproducibility and integrity of DNA methylation measurement. Patterns. (2020) 1:100014. doi: 10.1016/j.patter.2020.100014

79. Lander ES, Linton LM, Birren B, Nusbaum C, Zody MC, Baldwin J, et al. Initial sequencing and analysis of the human genome. Nature. (2001) 409:860-921. doi: 10.1038/35057062

80. Zhang X, Mathews CK. Effect of DNA cytosine methylation upon deamination-induced mutagenesis in a natural target sequence in duplex DNA. J Biol Chem. (1994) 269:7066-9. doi: 10.1016/S0021-9258(17)3 7246-0

81. Krokan HE, Drabløs F, Slupphaug G. Uracil in DNAoccurrence, consequences and repair. Oncogene. (2002) 21:893548. doi: 10.1038/sj.onc.1205996

82. Shoemaker R, Deng J, Wang W, Zhang K. Allele-specific methylation is prevalent and is contributed by CpG-SNPs in the human genome. Genome Res. (2010) 20:883-9. doi: 10.1101/gr.104695.109

83. Dayeh TA, Olsson AH, Volkov P, Almgren P, Rönn T, Ling C. Identification of CpG-SNPs associated with type 2 diabetes and differential DNA methylation in human pancreatic islets. Diabetologia. (2013) 56:103646. doi: 10.1007/s00125-012-2815-7

84. Chen J, Jiang Y, Zhou J, Liu S, Qin N, Du J, et al. Evaluation of CpGSNPs in miRNA promoters and risk of breast cancer. Gene. (2018) 651:18. doi: 10.1016/j.gene.2018.01.070
85. Chen X, Chen X, Xu Y, Yang W, Wu N, Ye H, et al. Association of six CpGSNPs in the inflammation-related genes with coronary heart disease. Hum Genomics. (2016) 10(Suppl. 2):21. doi: 10.1186/s40246-016-0067-1

86. Gibbs JR, van der Brug MP, Hernandez DG, Traynor BJ, Nalls MA, Lai SL, et al. Abundant quantitative trait loci exist for DNA methylation and gene expression in human brain. PLoS Genet. (2010) 6:e1000952. doi: 10.1371/journal.pgen.1000952

87. Numata S, Ye T, Herman M, Lipska BK. DNA methylation changes in the postmortem dorsolateral prefrontal cortex of patients with schizophrenia. Front Genet. (2014) 5:280. doi: 10.3389/fgene.2014.00280

88. Hannon E, Spiers H, Viana J, Pidsley R, Burrage J, Murphy TM, et al. Methylation QTLs in the developing brain and their enrichment in schizophrenia risk loci. Nat Neurosci. (2016) 19:48-54. doi: 10.1038/nn.4182

89. Lin D, Chen J, Perrone-Bizzozero N, Bustillo JR, Du Y, Calhoun VD, et al. Characterization of cross-tissue genetic-epigenetic effects and their patterns in schizophrenia. Genome Med. (2018) 10:13. doi: 10.1186/s13073-018-0519-4

90. Gamazon ER, Badner JA, Cheng L, Zhang C, Zhang D, Cox NJ, et al. Enrichment of cis-regulatory gene expression SNPs and methylation quantitative trait loci among bipolar disorder susceptibility variants. $\mathrm{Mol}$ Psychiatry. (2013) 18:340-6. doi: 10.1038/mp.2011.174

91. Zhang C, Zhang R, Chen Z, Chen J, Ruan J, Lu Z, et al. Differential DNA methylation profiles of human B lymphocytes and Epstein-Barr virus-immortalized B lymphocytes. Chinese J Cancer Res. (2018) 30:10411. doi: $10.21147 /$ j.issn.1000-9604.2018.01.11

92. Starnawska A, Demontis D, Pen A, Hedemand A, Nielsen AL, Staunstrup $\mathrm{NH}$, et al. CACNA1C hypermethylation is associated with bipolar disorder. Transl Psychiatry. (2016) 6:e831. doi: 10.1038/tp.2016.99

93. Barbu MC, Shen X, Walker RM, Howard DM, Evans KL, Whalley HC, et al. Epigenetic prediction of major depressive disorder. Mol Psychiatry. (2020) 1-12. doi: 10.1038/s41380-020-0808-3

94. Hammerschlag AR, Byrne EM, eQTLGen Consortium, BIOS Consortium, Bartels M, Wray NR, et al. Refining attention-deficit/hyperactivity disorder and autism spectrum disorder genetic loci by integrating summary data from genome-wide association, gene expression, and DNA methylation studies. Biol Psychiatry. (2020) 88:470-9. doi: 10.1016/j.biopsych.2020. 05.002

95. Lin H, Wang F, Rosato AJ, Farrer LA, Henderson DC, Zhang H. Prefrontal cortex eQTLs/mQTLs enriched in genetic variants associated with alcohol use disorder and other diseases. Epigenomics. (2020) 12:789800. doi: 10.2217/epi-2019-0270

96. Byrne EM, Zhu Z, Qi T, Skene NG, Bryois J, Pardinas AF, et al. Conditional GWAS analysis to identify disorder-specific SNPs for psychiatric disorders. Mol Psychiatry. (2020) 1-12. doi: 10.1038/s41380-020-0705-9

97. Andrews SV, Sheppard B, Windham GC, Schieve LA, Schendel DE, Croen LA, et al. Case-control meta-analysis of blood DNA methylation and autism spectrum disorder. Mol Autism. (2018) 9:40. doi: 10.1186/s13229-018-0224-6

98. Mooney MA, Ryabinin P, Wilmot B, Bhatt P, Mill J, Nigg JT. Large epigenome-wide association study of childhood ADHD identifies peripheral DNA methylation associated with disease and polygenic risk burden. Transl Psychiatry. (2020) 10:1-12. doi: 10.1038/s41398-020-0710-4

99. Aberg KA, Shabalin AA, Chan RF, Zhao M, Kumar G, van Grootheest G, et al. Convergence of evidence from a methylome-wide CpG-SNP association study and GWAS of major depressive disorder. Transl Psychiatry. (2018) 8:162. doi: 10.1038/s41398-018-0205-8

100. van den Oord EJCG, Clark SL, Xie LY, Shabalin AA, Dozmorov MG, Kumar G, et al. A whole methylome CpG-SNP association study of psychosis in blood and brain tissue. Schizophr Bull. (2016) 42:101826. doi: $10.1093 / \mathrm{schbul} / \mathrm{sbv} 182$

101. Taqi MM, Bazov I, Watanabe H, Sheedy D, Harper C, Alkass K, et al. Prodynorphin CpG-SNPs associated with alcohol dependence: elevated methylation in the brain of human alcoholics. Addict Biol. (2011) 16:499509. doi: 10.1111/j.1369-1600.2011.00323.x

102. Bani-Fatemi A, Gonçalves VF, Zai C, de Souza R, Le Foll B, Kennedy JL, et al. Analysis of CpG SNPs in 34 genes: association test with suicide attempt in schizophrenia. Schizophr Res. (2013) 147:262-8. doi: 10.1016/j.schres.2013. 04.018 
103. Bird A. DNA methylation patterns and epigenetic memory. Genes Dev. (2002) 16:6-21. doi: 10.1101/gad.947102

104. Wagner JR, Busche S, Ge B, Kwan T, Pastinen T, Blanchette M. The relationship between DNA methylation, genetic and expression interindividual variation in untransformed human fibroblasts. Genome Biol. (2014) 15:R37. doi: 10.1186/gb-2014-15-2-r37

105. Gutierrez-Arcelus M, Lappalainen T, Montgomery SB, Buil A, Ongen H, Yurovsky A, et al. Passive and active DNA methylation and the interplay with genetic variation in gene regulation. Elife. (2013) 2:e00523. doi: 10.7554/eLife.005 23.024
Conflict of Interest: The authors declare that the research was conducted in the absence of any commercial or financial relationships that could be construed as a potential conflict of interest.

Copyright (c) 2021 Starnawska and Demontis. This is an open-access article distributed under the terms of the Creative Commons Attribution License (CC BY). The use, distribution or reproduction in other forums is permitted, provided the original author(s) and the copyright owner(s) are credited and that the original publication in this journal is cited, in accordance with accepted academic practice. No use, distribution or reproduction is permitted which does not comply with these terms. 